\title{
Türk Çocuklarında Ortodontik Lokal Maloklüzyon Risk Faktörlerinin Radyografik Olarak Değerlendirilmesi
}

\author{
Şirin Hatipoğlu(0000-0001-5466-2876) ${ }^{\alpha}$, Emire Aybüke Erdur(0000-0002-1887-8474) ${ }^{\beta}$
}

Selcuk Dent J, 2021; 8: 133-139 (Doi: 10.15311/selcukdentj.861666)

Bașvuru Tarihi: 16 Aralık 2019 Yayına Kabul Tarihi: 05 Haziran 2020

\begin{abstract}
Öz
Türk Çocuklarında Ortodontik Lokal Maloklüzyon Risk Faktörlerinin Radyografik Olarak Değerlendirilmesi

Amaç: Bu çalıșmanın amacı, 6-12 yaş aralığında bulunan Türk çocuklarının lokal ortodontik maloklüzyon risk faktörleri açısından, panoramik radyograflar üzerinde değerlendirilmesi ve gerekli koruyucu önleyici tedavi ihtiyaçlarının belirlenmesidir.

Gereç ve Yöntemler: Çalışma, 2008-2014 yılları arasında doğmuş olan 425 Türk çocuğunun panoramik radyografları üzerinden yürütüldü. Kayıtlar, Konya ve İstanbul'da bulunan kliniklere tedavi ve muayene amacıyla başvurmuş hasta kayıtları arasından elde edildi. Daimi diş boyutu, şekil ve pozisyon anomalilerinin yanı sıra; süt ve daimi dişlenmeye ait; diş sayısı, çürük, çekim/erken çekim, dolgu ve kanal dolgulu dişler ve yer tutucu varlığı değerlendirildi. İstatistiksel olarak prevalans hesaplamaları yapıldı. İki merkez arasındaki istatistiksel prevalans farklıı̆ı, iki bağımsız örneklem için oran testi (Z) ile değerlendirildi.
\end{abstract}

Bulgular: Çürük süt dişi (sd) ve dolgulu sd varlığı sırası ile; \% 20.6 ve \% 9.5 olarak, en yüksek prevalansa sahip parametreler olarak tespit edilmiştir. Buna karşlık, en az prevalans fazla sd ve çekilmiş daimi diş (dd) parametrelerinde, sırası ile \% 0.023 ve \% 0.036 olarak hesaplanmıştır. İki merkez arasında karşılaştırma yapıldığında, Konya'da; yer tutucu, çürük sd, dolgulu sd, çürük dd ve erken çekilmiş sd'nin prevalans yüzdeleri istatistiksel olarak İstanbul'dan yüksek çıkmıştır. Buna karşıllı, rezidüel kök, şekil dd ve kanal sd'nin prevalansları İstanbul'da istatistiksel olarak yüksek çıkmıştır.

Sonuç: Kazanılmış ortodontik maloklüzyonların önlenmesinde, koruyucu-önleyici diş tedavisinin önemi çok büyüktür. Çalışmamızda, özellikle koruyucu-önleyici tedavi ve ağız diş sağlığı eğitim intiyacı yüksek bulunmuştur. Bu nedenle, ağız ve diş sağlığı eğitimine özel önem ve dikkat gösterilmelidir.

\section{ANAHTAR KELIMELER}

Koruyucu ortodonti, Lokal risk faktörleri, Ortodontik maloklüzyon

Ortodontik maloklüzyon oluşturan faktörler genel ve lokal olarak ikiye ayrılmaktadır. ${ }^{1-5}$ Kalıtım, doğumsal anomaliler, travma, fonksiyonel bozukluklar ve kötü alışkanlıklar genel faktörler arasında sayılmaktadırlar. ${ }^{1,2}$ Diş sayı (eksiklik/fazlalık) anomalileri, diş boyut ve şekil anomalileri, diastema, süt dişlerinin erken kaybı ve yer koruma, süt dişi retansiyonu, ankiloz, yetersiz veya doğru olmayan klinik uygulamalar da lokal faktörler arasında

\section{ABSTRACT}

Radiographic Evaluation of Local Orthodontic Malocclusion Risk Factors of Turkish Children

Background: Aim of the study was to evaluate the Orthodontic malocclusion local risc factors of 6 to 12 years old Turkish children on Panoramic radiographs and also to estimate the preventive treatment needs.

Methods: Study was conducted on 425 Turkish children's Panoramic radiographs, born between 2008 - 2014 years. Records were obtained from 2 centers, located in Konya and istanbul. Besides permanent tooth size and form anomalies; tooth number, decays, extractions and fillings, root canal treatments of primary and permanent dentitions and space maintainers were evaluated. Statistical prevalence calculations were made. The statistical prevalence difference between the centers was tested with the ratio test $(Z)$ for two independent samples.

Results: The highest prevalence were found to belong to decayed $(20.6 \%)$ and filled $(9.5 \%)$ primary teeth parameters. On the other hand, the least prevalence was calculated as $0.023 \%$ and $0.036 \%$ in excess primary teeth and extracted permanent teeth parameters, respectively. In a comparison made between two centers, the prevalence percentages of space maintainers, decayed, filled and early extracted primary teeth and decayed permanent teeth in Konya were found to be statistically higher. On the other hand, the prevalence of residual roost, shape of permanent teeth and primary teeth with rooth canal fillings were found to be statistically higher in Istanbul.

Conclusion: Preventive dental care is very important for elimination of acquired orthodontc malloclusions. Need of preventive care and oral health education was found to be very high. Special attention and importance must be paid to the oral and dental health education.

\section{KEYWORDS}

Preventive orthodontics, Local risc factors, Orthodontic malocclusion

sayılmaktadır. ${ }^{1-3}$

Lokal etyolojik faktörlerin, ortodontik maloklüzyon oluşturmasına katkıları tek tek incelendiğinde, diş sayı anomalilerinden, süpernümere dişlerin görülme sıklı̆ı̆ını erkeklerde ve daimi dişli dönemde daha fazla olduğu bildirilmiştir. ${ }^{2,4}$ Konjenital diş eksikliği sırası ile üçüncü büyük azı, üst yan kesici, alt ikinci küçük azı ve alt kesici dişlerde görüldüğü belirtilmiştir. ${ }^{1,2,4}$ Diş sayısındaki fazlalığın; çapraşıklığa, overjete veya her

\footnotetext{
${ }^{\alpha}$ Beykent Üniversitesi, Diş Hekimliği Fakültesi, Ortodonti AD, İstanbul, Türkiye

$\beta$ Necmettin Erbakan Üniversitesi, Diş Hekimliği Fakültesi, Ortodonti AD, Konya, Türkiye
} 
ikisinin kombinasyonuna, eksikliğin ise; diastema, diş kaymaları ve buna bağlı olarak kapanış bozukluklarına sebep olduğu bilinmektedir. Diş boyut ve şekil anomalilerinden megadont dişlerin, en fazla daimi üst kesici dişlerde görüldüğü; çapraşıklık, overjet veya her ikisinin kombinasyonuna sebep olduğu bildirilmiştir. ${ }^{1,2}$ Füzyon dişlerin daimi dişli dönemde görülme sıklığının süt dişli döneme göre daha fazla olduğu, daimi dişli dönemde görülme sıklığının \% 0.1 ile 0.2 arasında değiştiği, her iki cinste görülme sıklığının eşit olduğu ve kesici dişlerin bu durumdan diğer dişlere kıyasla daha fazla etkilendiği gösterilmiştir., ${ }^{1,2,4}$ Mikrodontinin ise Down Sendromu ile Ektodermal Displazide görülen hypodonti ile ilişkili olarak görüldüğü bildirilmiştir. ${ }^{2,4}$

Yaygınlık ve şiddetinin zamanla azalma eğiliminde olmasına rağmen, süt dişi çürükleri hala birçok ülkenin temel halk sağlığı problemini oluşturmaya devam etmekte ve doğal daimi diş sürmesi öncesinde süt dişi çekimini gerektirmektedir. ${ }^{3}$ Süt dişlerinin erken kaybı ile birlikte bu yerin korunamaması durumunda, daimi diş diziliminde bozukluklar oluşturarak, ark boyu ve uzunluğunun kısalmasına bağlı olarak oluşan "semptomatik" yer darlığına sebep olmaktadır. ${ }^{1,4} \mathrm{Bu}$ durumun ortodontik bozukluğa sebep olma potansiyelinde olduğu veya ortodontik tedavi intiyacını arttırdığı pek çok çalışma ile gösterilmiştir. ${ }^{5-10}$ Tek taraflı erken mandibular süt dişi kaybı, sıklıkla kayıp tarafa doğru orta hattın kayması ile sonuçlanmaktadır. Çift taraflı erken süt kanin dişi kaybında ise ön daimi keserler belirgin bir şekilde linguale ve distale devrilir; kapanış derinleşir, overjet artar, ark perimetresinde belirgin bir kayıp meydana getirir, bu durum daimi diş diziliminde bozukluğa sebep olmaktadır. ${ }^{1,4}$

Süt dişleri çiğneme fonksiyonunu yerine getirmesinin yanı sıra, doğal yer tutucu olarak da görev yapmaktadırlar. Bu nedenle, süt dişlerinin orijinal mezio-distal boyutunun korunması çok önemlidir. Süt dişlerindeki çürükler ile süt dişlerine yapılmış yanlış restorasyonlar, orijinal meziodistal boyutun korunamamasına, yer kaybına ve çapraşıklığa neden olmaktadır. Eğer çürük bir süt dişine restorasyon yapılma şansı yoksa, çekim yapılıp ardından hemen yer tutucu uygulanması gerekmektedir. ${ }^{4}$

Bhujel ve ark. ${ }^{11}$, Ortodontik Tedavi İhtiyacı Endeksi (IOTN) hesaplayarak yaptıkları çalışmada, erken çekilmiş her bir süt dişinin, maloklüzyon oluşturma oranını \%18 arttırdığını bildirmişlerdir. Böylece, süt dişli dönemden daimi dişli döneme geçiş boyunca süt dişlerinin bakımı ve korunması, özellikle ark boyu perimetre kaybını önlemek, nihai maloklüzyon oluşumunu sınırlandırmak ve oluşabilecek ortodontik tedavi gerekliliğini en aza indirgemek açısından önerilmiştir. ${ }^{12,13} \mathrm{Bu}$ bilgiler ışığında, çalışmamızda, 612 yaş aralığında bulunan Türk çocuklarının, lokal ortodontik maloklüzyon risk faktörlerinin prevalansları ile birlikte, 2 merkez açısından bulgularda fark varlığını panoramik radyograflar üzerinde değerlendirmeyi amaçladık.

\section{GEREÇ VE YÖNTEMLER}

Diş hastalıkları, oral sağlık ve lokal faktörler açısından değerlendirilmenin yapıldığı, epidemiyolojik çalışmamız, 2008-2014 yılları arasında doğmuş, 425 Türk çocuğunun panoramik filmleri üzerinde yürütüldü. Çalışmanın etik onayı Necmettin Erbakan Üniversitesi Diş Hekimliği Fakültesi İlaç ve Tıbbi Cihaz Dışı Araştırmalar Etik Kurulu tarafından onaylandı (2020/02). Röntgen kayıtları, Konya ve İstanbul olmak üzere, 2 merkezden toplandı. Konya'daki kayıtlar Necmettin Erbakan Üniversitesi Diş Hekimliği Fakültesi Ortodonti Anabilim Dalı'ndan, İstanbul'daki kayıtlar aynı bölgede bulunan 3 özel klinikten; tedavi ve muayene amaçlı başvurmuş hastaların kayıtları arasından seçildi. İstanbul'dan 192 hastanın röntgen filmi üzerinde 2123 süt dişi (sd) ile 2301 daimi diş (dd); Konya'dan da 233 hastanın röntgen filmi üzerinde 2086 sd ile 3270 dd; totalde her 2 şehirden 425 hastanın röntgen filmleri üzerinde 4209 sd ve 5571 dd değerlendirildi.

Röntgenlerin değerlendirilmesi aşamasında:

- Diagnostik kaliteye sahip olmayan artefaktlı görüntü kayıtları,

- Belirtilen yıllar dışında doğmuş olan hasta kayıtları,

- Eksik veriye (doğum tarihi, röntgen çekim tarihi veya cinsiyet bilgisi) sahip kayıtlar,

- Türk kökenli olmayan hasta kayıtları çalışma dışı bırakıldı.

Daimi diş boyut, şekil ve pozisyon anomalilerinin yanı sıra; süt ve daimi dişlenmeye ait: diş sayı (eksik/fazla), çürük, çekim/ erken çekim, dolgu ve kanal dolgusu yapılmış dişler ve yertutucu varlığı gibi 18 parametre iki araştırmacı tarafından ölçümleme (kalibrasyon) işlemlerini takiben değerlendirildi. Her bir parametreye ait sonuçlar, süt ve daimi dişli dönemlerin her ikisi için; sağ üst diş bölgesi 1, sol üst diş bölgesi 2, sol alt diş bölgesi 3 ve sağ alt diş bölgesi 4 olarak numaralandırılarak veri tablosuna işlendi.

Elde edilen sonuçların bölgesel ve total prevalans hesaplamaları yapıldı. Her bir parametre için prevalanslar arası ve 2 merkez açısından bulgularda farklılık değerlendirildi. Ayrıca 2 merkez arasında farklı çıkan parametreler için istatistiksel prevalans farklılığı iki bağımsız örneklem için oran testi $(Z)$ ile test edildi.

\section{BULGULAR}

Total sonuçları değerlendirdiğimizde, çürük sd ve dolgulu sd varlığı sırası ile: \% 20.6 ve \% 9.5 olarak, en yüksek prevalansa sahip parametreler olarak tespit edilmiştir. Bu parametreleri takiben, yüksek prevalans açısından, pozisyon dd bozuklukları \% 3.698 ve çürük 
dd \% 2.746 parametreleri 3. ve 4. sırada gelmektedir. Buna karşlık, en düşük prevalans, fazla sd ve çekilmiş dd parametrelerinde, sırası ile \% 0.048 ve \% 0.036 olarak hesaplanmıştır (Tablo1).

Tablo 1.

\section{İstanbul, Konya ve her 2 şehir için incelenen parametrelerin bölgesel / total Frekans ve Yüzdelikleri ile İlgili oldukları diş(ler)}

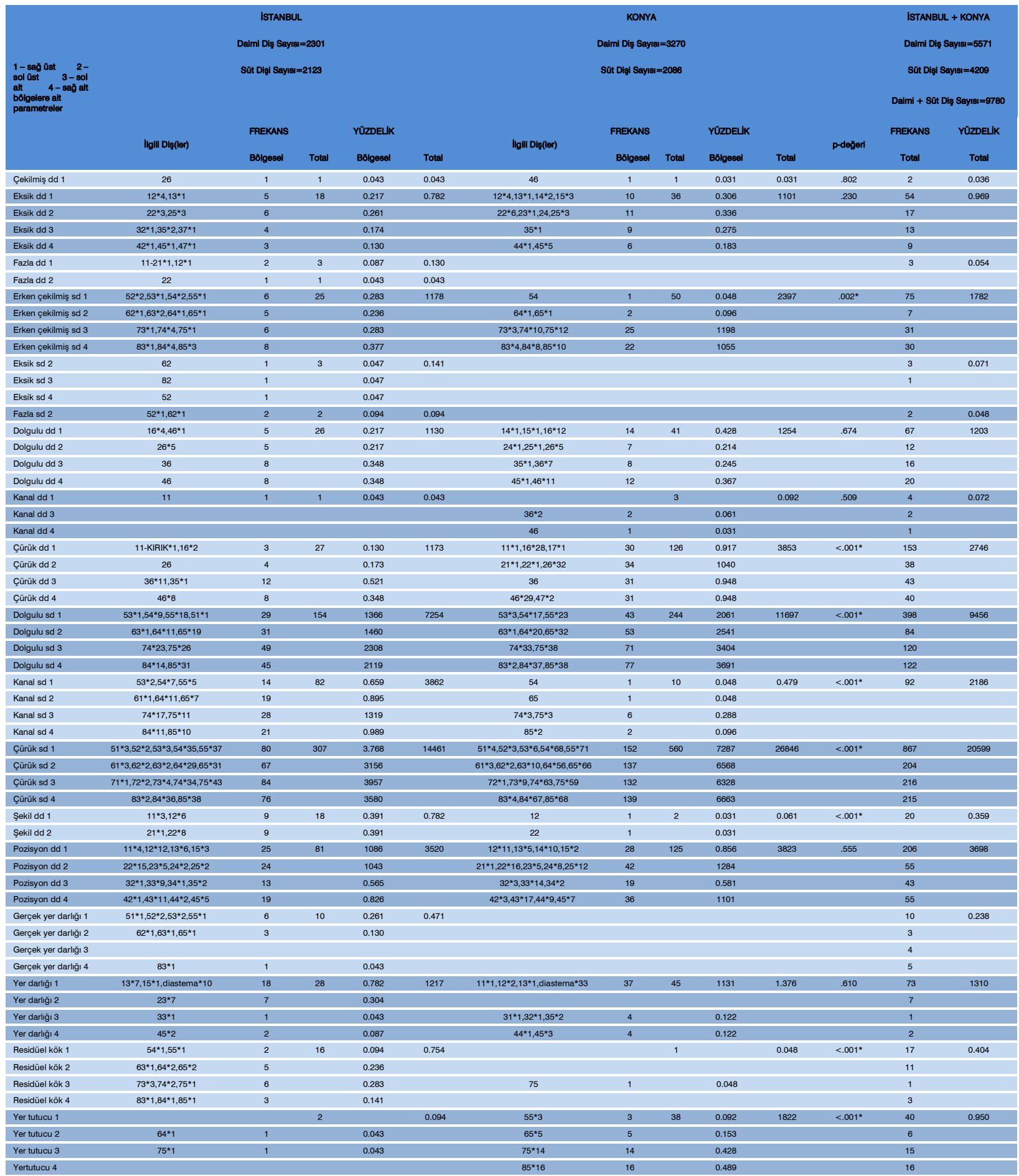


Bölgesel değerlendirmelere baktığımızda çürük sd, dolgulu sd, çürük dd, pozisyon dd, erken çekilmiş sd, yer tutucu, yer darlığı, dolgulu dd, eksik dd ve kanal dd parametrelerinin Konya'da; kanal sd, şekil dd, rezidüel kök, gerçek yer darlığı, eksik sd, fazla dd, fazla sd ve çekilmiş dd parametrelerinin İstanbul'da daha yüksek oldukları tespit edilmiştir (Tablo 1). Ancak, istatistiksel olarak, iki merkez arasında prevalans karşılaştırması yapıldığında: yer tutucu $\left(p<0.001^{\star}\right)$, çürük sd $\left(p<0.001^{\star}\right)$, dolgulu sd $\left(p<0.001^{\star}\right)$, çürük $d d\left(p<0.001^{\star}\right)$ ve erken çekilmiş sd $\left(p=0.002^{\star}\right)$ prevalans yüzdelerinin Konya'da istatistiksel olarak daha yüksek; rezidüel kök $\left(p<0.001^{\star}\right)$, şekil dd $\left(p<0.001^{\star}\right)$ ve kanal sd $\left(p<0.001^{*}\right)$ prevalanslarının ise İstanbul'da daha yüksek çıktığı tespit edilmiştir (Tablo 2).

Tablo 2.

\section{Istanbul, Konya ve her 2 şehir için total Frekans ve Yüzdelik ile $p$ değeri}

\begin{tabular}{|c|c|c|c|c|c|c|c|c|}
\hline & isTANBUL & & KONYA & & & iSTANBUL + KONYA & & \\
\hline & Daimi Diş Sayısı = & 2301 & Daimi Diş Sayısı = & 3270 & & Daimi Diş Sayısı = & 5571 & \\
\hline & Süt Dişi Sayısı= & 2123 & Süt Dişi Sayısı = & 2086 & & Süt Dişi Sayısı= & 4209 & \\
\hline & & & & & & Daimi + Süt Diş Sayısı= & 9780 & \\
\hline & FREKANS & YÜZDELIK & FREKANS & YÜZDELIK & p-değeri & FREKANS & & YÜZDELiKK \\
\hline Çekilmiş dd & 1 & 0.043 & 1 & 0.031 & .802 & 2 & & 0.036 \\
\hline Eksik dd & 18 & 0.782 & 36 & 1101 & .230 & 54 & & 0.969 \\
\hline Fazla dd & 3 & 0.130 & & & & 3 & & 0.054 \\
\hline $\begin{array}{l}\text { Erken } \\
\text { çekilmiş sd }\end{array}$ & 25 & 1178 & 50 & 2397 & $.002^{*}$ & 75 & & 1782 \\
\hline Eksik sd & 3 & 0.141 & & & & 3 & & 0.071 \\
\hline Fazla sd & 2 & 0.094 & & & & 2 & & 0.048 \\
\hline Dolgulu dd & 26 & 1130 & 41 & 1254 & .674 & 67 & & 1203 \\
\hline Kanal dd & 1 & 0.043 & 3 & 0.092 & .509 & 4 & & 0.072 \\
\hline Çürük dd & 27 & 1173 & 126 & 3853 & $<.001^{*}$ & 153 & & 2746 \\
\hline Dolgulu sd & 154 & 7254 & 244 & 11697 & $<.001^{*}$ & 398 & & 9456 \\
\hline Kanal sd & 82 & 3862 & 10 & 0.479 & $<.001^{*}$ & 92 & & 2186 \\
\hline Çürük sd & 307 & 14461 & 560 & 26846 & $<.001^{*}$ & 867 & & 20599 \\
\hline Şekil dd & 18 & 0.782 & 2 & 0.061 & $<.001^{*}$ & 20 & & 0.359 \\
\hline Pozisyon dd & 81 & 3520 & 125 & 3823 & .555 & 206 & & 3698 \\
\hline $\begin{array}{l}\text { Gerçek yer } \\
\text { darlığı }\end{array}$ & 10 & 0.471 & & & & 10 & & 0.238 \\
\hline Yer darlığı & 28 & 1217 & 45 & 1.376 & .610 & 73 & & 1310 \\
\hline $\begin{array}{l}\text { Residüel } \\
\text { kök }\end{array}$ & 16 & 0.754 & 1 & 0.048 & $<.001^{*}$ & 17 & & 0.404 \\
\hline Yer tutucu & 2 & 0.094 & 38 & 1822 & $<.001^{*}$ & 40 & & 0.950 \\
\hline
\end{tabular}

Çürük sd ve dolgulu sd, en yüksek prevalansa sahip parametreler olup, Konya'da istatistiksel olarak İstanbul'a göre daha yüksek bulunmuştur $\left(p<0.001^{*}\right.$, Tablo 1,2). Buna karşılık olarak, en düşük prevalansa sahip parametrelerden fazla sd sadece İstanbul'da tespit edilmiş olup; çekilmiş dd için iki merkez arasında istatistiksel olarak anlamlı bir fark olmaksızın sadece prevalans olarak İstanbul'da daha yüksek olduğu tespit edilmiştir.

En fazla çürük sd'leri molarlar olarak $(54,55,64,65,74,75,84,85)$ alt-üst posterior bölgelerde bulunmuştur (Tablo 1). 


\section{TARTIŞMA}

Çalışmamızda, total çürük sd verileri (\% 20.599) en yüksek prevalans olarak bulunmuştur. Iki merkez için ayrı ayrı değerlendirildiğinde; Konya için \% 26.846 ve İstanbul için de \% 14.461 olarak tespit edilmiş olup, istatistiksel olarak anlamlı bulunmuştur. En fazla çürük sd'leri molarlar olarak $(54,55,64,65,74,75,84,85)$ alt-üst posterior bölgelerde bulunmuştur. Çürük posterior süt dişi varlığında, Leeway yer rezervleri fazlasıyla kullanılarak posteriorda bulunan dişler mezialize olur ve alttan gelecek daimi dişlerin yerlerini işgal ederek, semptomatik çapraşıklığa sebep olur. Tedavi edilmemiş çürük sd'leri, bu nedenle ortodontik maloklüzyon oluşumunda önemli bir rol oynamaktadırlar. Bu bulgu bize ayrıca, çocukların diş fırçalama esnasında, bu dişlere ulaşmada ve temizlemede zorluk çektiğinin göstergesidir. Çocuklara ve ailelere diş fırçalama eğitimi verilirken, bu bulgunun göz önünde bulundurulması önem arz etmektedir. Ebeveyinlerin fırçalama esnasında, çocuğa gözetmenlik yapması ve onu yönlendirmesi tavsiye edilmelidir. Gökalp ve ark. ${ }^{14}$ yapmış oldukları araşıımada çürük prevalansını 5 yaşındaki erkek çocuklarda \% 73.1; 15 yaşındaki kız çocuklarında da \% 59.5 olarak bildirmişlerdir. Bizim çalışmamızdaki çürük prevalansları, bu çalışmaya göre oldukça düşük bulundu. Çalışma verileri arasındaki fark, Gökalp ve ark. ${ }^{14}$, nın çalşımayı 15 yıl önce yapmış olmaları ve geçen zamanda, Türk toplumunun ağız-diş sağlığının önemi bakımından bilinçlenmiş olabileceğini düşündürmektedir. Ayrıca, gelişmiş ülkelerde diş çürüğü prevalansındaki düşüş ${ }^{15-17}$, gelişmekte olan ülkelerde aynı belirginlikte olmaması da göz önünde bulundurulmalıdır. ${ }^{3,18}$

Çalışmamızda, total dolgulu sd prevalansını \% 9.456, en yüksek 2. prevalans olarak; Konya için \% 11.697 ve İstanbul için de \% 7.254 olarak bulunmuştur. İki merkez veri karşılaştırımasında, bu parametre için, istatistiksel olarak anlamlı bir fark bulunmuştur. Dolgulu sd prevalansının yüksek bulunması, ailelerin genel olarak, dd'leri önemseyip, sd'lerini "değişecek, geçici dişler" algısının değiştiğini ve bu dişlere de gerekli önemin verildiğini göstermektedir. Ancak yine de, total çürük sd'lerine göre total dolgulu sd ve total kanal sd oranlarının sırası ile \% 29.3 ve \% 6.8 olduğu göz önünde bulundurulursa; bu oranların oldukça düşük olduğu görülmektedir. Buna bağlı olarak, küçük yaş grubu çocuklar için gerekli olan koruyucu ve önleyici tedavi gereksinimleri ile birlikte, ağız ve diş sağlığı hizmetlerinin, ayrıca aile-ebeveyin-toplum bazında ağızdiş sağlığı eğitiminin geliştirilmesi için daha çok çalışmamız gerektiği ortaya çıkmaktadır. Aileleri sd'lerinin önemi ve ortodontik maloklüzyon oluşmasına sağladıkları etkiler konusunda eğitmemiz şart.

Çalışmamızda, en yüksek total 3. prevalans olarak (\% 3.698), pozisyon dd'lerdeki farkllık bulundu. Tüm dd dizisindeki dişler bu prevalansın yüksek çıkmasında katkıda bulunmuştur. Bu parametre, ortodontik maloklüzyon oluşumuna doğrudan katkı sağlamakadır.

Total çürük dd prevalansı, en yüksek 4. prevalans (\% 2.746) olarak bulunmuş olup; Konya için \% 3.853 ve İstanbul için de \% 1.173 olarak gözlenmiştir. Iki merkez açısından değerlendirdiğimizde, sonuçlar istatistiksel olarak anlamlı bulunmuştur. Konya'daki çürük dd prevalansı İstanbul'daki prevalanstan istatistiksel olarak yüksek çıkmıştır. Her ne kadar total çürük dd prevalansı sıralamada, 4. en yüksek prevalans olarak tespit edilmiş olsa da, bu oran total çürük sd prevalansı (\% 20.599) ile karşılaştırıldığında oldukça düşük bulunmuştur. Buradan ailelerin daimi dişleri önemsedikleri, ağız hijyenine süt dişli döneme göre çok daha fazla özen gösterdikleri sonucunu çıkartabiliriz. Verilerimizde en fazla çürüyen dd, 4 bölgede (sağ alt) 1. molarlar olarak tespit edilmiştir. Bu dişlerin, ilk süren dd'ler arasında olmaları, aileler tarafından süt dişleri ile karıştırımaları ve ağız içinde konum olarak en geride bulunmalarından dolayı, bu dişlerin temizliğinin yeterli olarak sağlanamadığı, görüşleri sonuçlarımızla da örtüşmektedir. Total dolgulu dd oranının, total çürük dd'lere göre \% 30 olduğu göz önünde bulundurulursa, bu oranın yine sd'deki gibi oldukça düşük olduğu ve yükseltilmesi için çalışılması gerektiği ortaya çıkmaktadır.

Erken çekilmiş sd total prevalansı (\% 1.782) 6. en yüksek prevalans olarak tespit edilmiş, Konya'daki prevalans (\% 2.397) İstanbul'dakine (\% 1.178) göre istatistiksel olarak yüksek bulunmuştur. Erken çekilmiş sd'leri yine en fazla molarlar olarak alt-üst posterior bölgelerde bulunmuştur. Buna bağlı olarak Konya'daki yer tutucu prevalansı (\% 1.822) İstanbul'a (\% 0.094) göre yine istatistiksel olarak daha fazla tespit edilmiştir. Totalde, erken çekilmiş sd'leri için, her 2 merkezde \% 35 oranında yer tutucu yapılmışır. İki merkez karşılaştııılığında yer tutucuların Konya (\% 43)'da, İstanbul (\% 7)'a göre daha fazla olması, Konya'daki verilerin Üniversite Hastanesi'nden alınmış olmasına bağlayabiliriz. Erken sd kaybının, çapraşıklık üzerinde etkili olduğu bilinmektedir. Bu nedenle özellikle koruyucu-önleyici tedavilerin, ortodontik maloklüzyon oluşturması açısından, önemi ortaya çıkmaktadır. 
Miyamoto ve ark. ${ }^{5}$ erken süt dişi kaybının, çapraşıklık ve kötü diş dizilimine olan etkilerini, 11 yaş ve üstü, daimi dişli dönemde olan 255 okul çocuğunda değerlendirmişlerdir. Bir veya daha fazla süt kanin veya molar diş kaybına sahip çocukların: büyük olasılıkla daimi dişli dönemde ortodontik tedaviye intiyaçları olacağını; erken süt molar kayıplarının özellikle daimi diş diziliminde bozukluklara sebep olan ana faktör olduğunu bildirmişlerdir.

Çalışma dizaynımızın retrospektif olması nedeniyle, hastalar beslenme ve fırçalama alışkanlığı açısından, aileler ise sosyo-ekonomik ve eğitim düzeyleri açısından değerlendirilememiş olup, bu çalışmamızın limitasyonunu oluşturmaktadır. Bu değerlendirmelerle birlikte yapılan çalışmaların sonuçları literatüre katkı sağlayacaktır.

Çalışmanın sonuçları göz önünde bulundurulduğunda, çürük sd prevalansının geçmiş yıllara oranla düşük çıkması, yer tutucu oranının yüksek olması, çocuklarda ağız bakımına verilen önemin artığını göstermektedir. Ancak yüksek çürük sd prevalansı, dolgulu sd oranının çürük sd'lerinin sadece \% 29'unu kapsıyor olması bizi düşündürmelidir. Özellikle sd'li dönemde bulunan çocuklar için gerekli olan koruyucu-önleyici tedavi gereksinimleri ile birlikte, ağız ve diş sağlığı hizmetlerinin, ayrıca aile-toplum ağız-diş sağlığı eğitiminin de etkili ve yeterli olarak sağlanabilmesi oluşacak ortodontik anomalilerin engellenmesi için önem arz etmektedir.

\section{SONUÇ}

Kazanılmış ortodontik maloklüzyonların önlenmesinde, koruyucu-önleyici diş tedavisinin önemi çok büyüktür. Hem bireysel, hem de toplumsal ortodontik tedavi masrafları, koruyucu-önleyici diş tedavilerinin uygulanması ile azaltılabilir. Koruyucu-önleyici tedavinin yanı sıra, ağız ve diş sağlığı eğitimine de özel önem ve dikkat gösterilmelidir.

\section{TEŞEKKÜR}

Dr. Muslu Kazım Korez'e çalışmamızın istatistiksel hesaplamalarını yaptığı ve katkı sağladığı için teşekkür ederiz. 


\section{KAYNAKLAR}

1. Erverdi N. Bölüm 2: Maloklüzyonların etyolojisi, Çağdaş Ortodonti, Editor Erverdi N., Quintessence Publishing Türkiye; 2017 s.25-48.

2. Heasman, P. Master Dentistry Volume 2: Restorative Dentistry, Paediatric Dentistry \& Orthodontics, 2nd Edition, Chapter. Orthodontics II: Management of occlusal problems, Churchill Livingstone, Elsevier; 2008; p.293-337.

3. Petersen PE. The World Oral Health Report 2003: continuous improvement of oral health in the 21st century - the approach of the WHO Global Oral Health Programme. Community Dent Oral Epidemiol. 2003;31(Suppl 1):3-23.

4. Dean JA; McDonald and Avery's Dentistry for the Child and Adolescent, 10th Edition, Chapter 22: Managing the Developing Occlusion, Mosby, 2016; p.415-478.

5. Miyamoto W, Chung CS, Yee PK. Effect of premature loss of deciduous canines and molars on malocclusion of the permanent dentition. J Dent Res. 1976;55:584590.

6. Northway WM, Wainright RL, Demirjian A. Effects of premature loss of deciduous molars. Angle Orthod. 1984;54:295-329.

7. Northway WM. The not-so-harmless maxillary primary first molar extraction. J Am Dent Assoc. 2000;131:1711-20.

8. Proffit WR, Fields HW, Sarver DM. Contemporary Orthodontics. 5th ed. St Louis: Mosby; 2013.

9. Mitchell L. An introduction to orthodontics. New York: Oxford University Press Inc.; 2007.

10. Melsen B, Terp S. The influence of extractions caries cause on the development of malocclusion and need for orthodontic treatment. Swed Dent J Suppl. 1982;15:163-9.

11.Bhujel N, Duggal M, Munyombwe T, Godson J, Day P. The effect of premature extraction of primary teeth on the subsequent need for orthodontic treatment. Eur Arch Paediatr Dent. 2014;15:393-400.

12. American Academy of Pediatric Dentistry. Guideline on management of the developing dentition and occlusion in pediatric dentistry. Clinical Affairs CommitteeDeveloping Dentition Subcommittee. Pediatr Dent. 2015;37(Suppl):253-65.

13. Royal College of Surgeons of England. Extraction of primary teeth-balance and compensation. Faculty of Dental Surgery Working Party. 2006. https://www.rcseng.ac.uk/fds/publicationsclinicalguidelines/clinical_guidelines/docu ments/extractp.pdf. Accessed 31 Dec 2015.

14.Gökalp S, Doğan BG, Tekçiçek $M$, Berberoğlu $A$, Ünlüer Ş. Beş, On İki ve On Beş yaş çocukların ağız diş sağlığı profili, Türkiye-2004. Hacettepe Diş Hekimliği Dergisi, 2007;31(4):3-10.
15. Nithila A, Bourgeois D, Barmes DE, Murtomaa $\mathrm{H}$. WHO Global Oral Data Bank, 1986-96: An overview of oral health surveys at 12 years of age. Bull World Health Organ. 1998;76(3):237-44.

16. Renson CE. Changing patterns of dental caries: a survey of 20 countries. Ann Acad Med Singapore. 1986;15(3):284-98.

17.Sheiham A. Strategies for oral health care. Euro Observer, 2005;7(3):1-4.

18. Edelstein, BL. The dental caries pandemic and disparities problem. BMC Oral Health 2006;6(Suppl 1):S2.

Yazışma Adresi:

Şirin HATIPOĞLU

Beykent Üniversitesi

Diş Hekimliği Fakültesi Ortodonti AD.

İstanbul, Türkiye

Tel : : +902124441997-6114

E Posta: sirinhatipoglu@beykent.edu.tr 